\title{
Legacy Beliefs Across Generations: Comparing Views of Older Parents and Their Adult Children
}

The International Journal of Aging and Human Development 2019, Vol. 88(2) 168-186

(C) The Author(s) 2018

Article reuse guidelines: sagepub.com/journals-permissions DOI: $10.1|77 / 009| 4 \mid 5018757212$ journals.sagepub.com/home/ahd

@SAGE

\section{Thomas M. Meuser', Thuli G. Mthembu ${ }^{\text {(D), }}$ Brianne L. Overton', Nicolette V. Roman', Rebecca D. Miller', Katharina P. Lyons' and Brian D. Carpenter ${ }^{3}$}

\begin{abstract}
This mixed-methods study examined legacy beliefs (i.e., anticipated remembrances and linkages to the self after death) as understood in 14 older parent and adult child pairs. This work validates and expands on a 2005 typology of legacy beliefs from gerontologists, Elizabeth Hunter and Graham Rowles. A structured interview was administered separately to parents and children, coded for legacy examples (i.e., those unique to the parent, overlapping, unique to the child), and analyzed with respect to expectations of similarity reported by each participant. Most predicted moderate to high overlap in mutual understanding of parent legacy. This was not the case, as there were far more unique legacy examples given than shared. Pairs agreed least with respect to material legacies, with half showing no agreement. All reported finding the structured discussion of legacy to be beneficial, with some indicating an intention to continue these discussions further. This work may constitute a new approach to intervention.
\end{abstract}

\footnotetext{
'University of Missouri-St. Louis, MO, USA

${ }^{2}$ University of the Western Cape, Cape Town, South Africa

${ }^{3}$ Washington University, St. Louis, MO, USA
}

\section{Corresponding Author:}

Thomas M. Meuser, University of Missouri-St. Louis, St. Louis, MO 63I2I, USA.

Email: meusert@umsl.edu 


\section{Keywords}

legacy beliefs, end of life, family, generational, life review, reminiscence

\section{Introduction}

A critical developmental process in late life is coming to terms with the totality of one's lived experiences in the face of death (Butler, 1963). Questions of impact, meaning, and legacy arise. Developmental theorist, Erik Erikson, described this stage in terms of a dichotomy: despair-integrity (Erikson \& Erikson, 1981; Erikson, 1963). The despairing person struggles to find lasting meaning or value in his life and thus questions the legacy he may leave behind. In contrast, the integrated person understands her life in broader, accepting terms. The whole of her life is "right" on a basic level, and she feels assured in what she passes on to future generations. This transmission of legacy was the focus of this investigation.

Gerontologists, Schaie and Willis (2000), describe this developmental phase as a period of "legacy creating." Personality and identity theorist, Dan McAdams (1996) frames it as an interactive process of "story-making" which occurs in the cultural context of one's immediate family and extended interpersonal network. Legacy is passed on through a shared, evolving story.

Older adults often grapple with questions of meaning and legacy through selfnarratives - spoken internally or expressed openly to others (Haight \& Haight, 2007). Narrative gerontologists study these stories to understand how older adults navigate this process (Randall \& Kenyon, 2004), and their findings guide informal and professional strategies to promote integration and wellbeing in advanced age (Garland \& Garland, 2001; Gibson, 2004). Various targeted reminiscence and broader life review interventions have been developed with this broad objective in mind (Ehlman \& Ligon, 2012; Kenyon, Bohlmeijer, \& Randall, 2011; Kunz \& Soltys, 2007; Meuser, 2011).

A component of most life review interventions is the identification of personal legacy beliefs: What about "me" will be remembered and have an impact after I die? How an individual answers this question has serious implications for emotional and existential well-being in the final days or years of life (Hunter, 2008).

A number of interventions targeting legacy and meaning have been proposed and tested in recent years. Gerontologist, Rebecca Allen (2009) developed a Legacy Project Intervention whereby dying persons and their family members collaborate on a shared legacy product. Open communication is central to her approach. Similarly, Dignity Therapy involves a series of interviews with a dying person to identify and transmit values and legacy beliefs to family via a written 
document (McClement et al., 2007). Sheehan and Donorfio (1999) targeted mother-daughter (patient-caregiver) dyads for a shared, meaning-oriented intervention with qualitative measurement of impact.

Hunter and Rowles (2005) developed a typology of legacy beliefs through a series of in-depth, semistructured interviews with 14 adults ranging in age from 31 to 94 years. Through a process of grounded coding, they identified three primary legacy types: values, material items/resources, and biological characteristics. Within each, three subtypes were described. Values may be of a personal nature (i.e., what "I" believe as a unique individual), social (i.e., societal values "I" hold dear), and cultural (i.e., ethnic beliefs and practices "I" care about). Material may be heirlooms (i.e., objects with generational family meaning), possessions (i.e., objects that "I" care about or say something about me), and symbols (i.e., an object that "I" may not own but that still says something about me). Finally, biological may refer to genetics (i.e., what "I" pass on in terms of traits and disease risk), health (i.e., "my" health attitudes, status and practices), and body (i.e., aspects of "my" body and its appearance).

To date, only a handful of studies have utilized this structure as the basis for formal research, and no validated measures of legacy beliefs have been published. Hunter (2008) utilized the typology in a qualitative study of legacy beliefs in older women. Zanjani, Downer, Hosier, and Watkins (2014) embedded the model in a feasibility study of "memory banking," a structured approach to record life stories and legacies for future generations. The typology has also informed works on environmental legacy (Zaval, Markowitz, \& Weber, 2015), attitudes about legacy at midlife (Newton \& Jones, 2016), meanings in family inheritance (de Witt, Campbell, Ploeg, Kemp, \& Rosenthal, 2013), and leadership styles (Zacher, Rosing, \& Frese, 2011).

How legacy beliefs are understood and communicated in the context of family relationships is unclear, as past studies sampled individuals and not family groups. de Witt et al. (2013) examined the reactions of adults from blended and nonblended families to the passing of material legacies. While they had some married couples in their study, within family communication - especially cross-generational dialogue - was not addressed. This raises a question: How are legacy beliefs understood across generations in families? If interviewed about legacy, would an older mother's description of her legacy be similar to that described from the perspective of an adult son? Or another parent-child combination?

In life review interviewing, the identification of legacy beliefs serves a therapeutic, developmental function for the interviewee (Meuser, 2011). Evidence of integrity - Erikson's final stage - is revealed and celebrated in a thorough interview. If agreed to by the elder in question, the inclusion of family members in the 
life review process can extend gains of understanding, acceptance, and wellbeing to immediate family members (Allen, 2009).

The concept of "family integrity" is applicable as well. King and Wynne (2004) proposed this concept to promote research on communication and cohesion in mature families:

The conceptualization of family integrity as an interaction of individual perceptions and observable family processes allows for a considerable degree of variability in the means by which an elder may arrive at a sense of familial peace and acceptance. (p. 17)

In the experience of one author, unless questioned directly, legacy beliefs often remain as the private thoughts and wishes of the individual (see Meuser, 2011). Few elders participate in formal life review interventions to give voice to these beliefs; most will reveal them informally, if at all. Those that do can find the process a bit daunting, as talking about legacy is not a cultural norm. While some may talk about these issues to family members, the extent to which this is done and how well these expressed beliefs are understood remain empirical issues for study.

Dying persons, in particular, need to know they are accepted and that their legacy is assured (Baker, 2004). Often this legacy includes spiritual and religious beliefs. Murray et al. (2004) conducted qualitative interviews with 40 terminally ill persons and their professional caregivers for more than 3 months. The dying persons evidenced strong needs for personal validation and spiritual understanding, but many of the professionals lacked the skills or time to provide for these needs. Families often look to health and social service professionals for guidance in care situations. How often are professionals encouraged to provide spiritual support (e.g., with respect to legacy)? This and other studies suggest a disconnection between the dying person's deeper developmental needs (as described earlier) and bodily care emphasized in today's medical culture.

The present qualitative study explored understandings of personal legacy, informed by the Hunter and Rowles Typology, in the context of older parent and adult child relationships. The focus was on parental legacy, as expressed independently by each member of a parent-child pair. Our interviews sought to address the following questions:

Q1. How do older parents and adult children understand personal legacy?

- Q1a. Are there tangible differences in these understandings within pairs and across groups (parents vs. children)?

Q2. Do older parents and their adult children express similar views of parental legacy (i.e., indicating shared mutual understanding)?

- Q2a. How are legacy categories distributed within pairs? 
- Q2b. How are legacy categories distributed across groups (parents vs. children)?

Q3. Did participants experience discussions of legacy in this study as beneficial?

\section{Method}

Parents (aged 60 years and older) and children (aged 20 and older) were recruited to participate in a single, recorded, structured interview with a member of the research team in Fall 2016 to Winter 2017. Volunteers were identified through a listing of past participants of the UMSL Life Review Project, ${ }^{1}$ through personal networks of team members, and by referral from social service professionals solicited through e-mail. Most pairs resided in the United States, with the exception of three pairs interviewed in South Africa as part of a cross-cultural faculty exchange program. ${ }^{2}$

An interview protocol was developed based on the Hunter \& Rowles Legacy Typology which followed a "funnel" approach for data collection (i.e., broad questions followed by more specific with probes). ${ }^{3}$ The interview started with questions about the parent-child relationship (e.g., quality of relationship, similarity of values, management of conflict) to build rapport and provide context. Next, a brief definition of legacy was presented:

All of us die eventually. While alive, we touch and impact the lives of others and the world around us. These impacts are often called "legacies." With this brief definition, what does "legacy" mean to you? How do you define it?

Participants were then asked to describe their own (parent) or their parent's (child) legacy in as much detail as they could. Clarifying questions were asked in some cases. The remaining interview followed the typology, starting with the three categories presented sequentially: values, material, and biological. Often, these discussions expanded on the examples just provided in response to the open-ended question about legacy. Next, handouts listing category subtypes were presented and each was discussed separately until no further legacy examples were offered. For values, an additional subtype was added to address an interest of a team member (i.e., spiritual-religious values). We judged this to be a "face valid" addition that yielded considerable discussion in some interviews.

The interview ended with the presentation of a 1 to 7 point overlap scale, with versions tailored to the parent or child perspectives. Parents were asked to guess how much their child's description of their legacy would overlap in content with what they had just shared $(7=$ total overlap; $1=$ little overlap $)$. In percentage terms, a rating of " 4 " would roughly equate to $40 \%$ to $50 \%$ overlap. Children guessed how much what they had shared would mirror that shared by their parents. Finally, participants were asked about their experience of the interview and what they learned or may have gained. 
Interviews were transcribed for content analysis and reviewed in combination with the original video footage (i.e., for nonverbal and affective context).

\section{Sample}

Fourteen parent-child pairs (28 individuals, 64\% females) participated: 11 White/Caucasian from St. Louis, Missouri, and 3 Mixed Race (self-described as "Colored") from Cape Town, South Africa (Pairs L, M, and N). The most common type was Mother-Daughter ( Father-Daughter (three-F, H, and L), Mother-Son (two-B and I), and Father-Son (two-D and G). Parent ages ranged from 64 to 84 years (Mean $=73, S D=5.8$ ) and child from 20 to 58 years (Mean $=44.1$, $S D=12.6)$. The age spread between parent and child was 20 to 52 years $($ Mean $=29.1, S D=8.9)$. Mean years of education for all participants were $16.5(S D=3.6)$, with no gender difference.

\section{Coding Process}

The primary unit of analysis was the pair. A two-step, consensus-based, grounded coding process was followed to code individual interviews first and then to examine overlap within pairs. First, legacy examples from each independent interview were identified and labeled based on consensus discussion of two to four team members. These were organized into the Hunter \& Rowles Typology. Certain legacy examples (e.g., my father's violin - material legacy, my mother's breast cancer - a biological legacy) fit neatly in the model, whereas others did not (e.g., my mother's sense of humor, my father's outspokenness, my skill as a woodworker).

As coding progressed, the team discussed and, by consensus, expanded the original typology. New subtypes were added to values (political and wisdom) and material (product and stories). A number of participants spoke of their strong political convictions. These seemed distinct from social or cultural values. Others spoke of rules for living that were not as much values as they were wise statements. A "product" subtype was added to reflect something made or produced. For example, a professor who participated emphasized her books as legacy objects. We heard numerous family stories that had a material quality, in that they were told and retold, and so were distinct legacies to be passed on. A new primary category - personality - addressed stylistic and behavioral legacies that could not be coded in the original model (e.g., sense of humor, sarcastic style, explosive temper).

A second, consensus "overlap phase" of coding followed. At least three team members participated in this phase for all pairs. Parent and child code lists were compared side by side for overlap in meaning. One daughter said her father's "love of music" is a legacy. The father emphasized a desire to pass on an 
"appreciation for music" as part of his legacy. An overlap code of music appreciation was generated and placed in the center of a Venn diagram for this pair.

Other codes required interpretation, and the consensus approach was especially helpful for these. In each case, the team member who conducted the interviews was present for the pair being discussed. The original transcript and video were also available for secondary review. Codes that addressed similar content were relabeled and recorded in the overlap of the Venn diagram. Codes that were substantially different or not present in one list went to the sides (parent only and child only). The grounded and overlap coding grids for Mother-Daughter, Pair K, are presented in Figure 1.

\begin{tabular}{|l|l|l|l|}
\hline \multicolumn{2}{|c|}{ Mother } & \multicolumn{2}{c|}{ Daughter } \\
\hline Close Family Relationships & Outspoken on Discrimination & Independence & Flag \\
\hline Genealogy Research & Open-minded to Ideas & Career Accomplishment & Family Photos \\
\hline Independence & Funds & DIY Person & Japanese Meal Tradition \\
\hline Loyalty to One Another & Double Secretary & Education & Star Wars Posters \\
\hline "Do-it-Yourself" Style & Crystal Cracker Barrel & Patriotism & Short Stature \\
\hline Acceptance of Diversity & Grandmother's Clock & Doing Right & Good Health \\
\hline Golden Rule & Japanese China & Caring for Others & Math Gene \\
\hline Goodness of Spirituality & Short Stature & Holiday Meal Tradition & Poor Eyesight \\
\hline Japanese Family Dinners & Longevity & Genealogy Research & \\
\hline Positive Attitude & Good Health & Bibles & \\
\hline Tough/Resilient & & Wedding Rings & \\
\hline
\end{tabular}

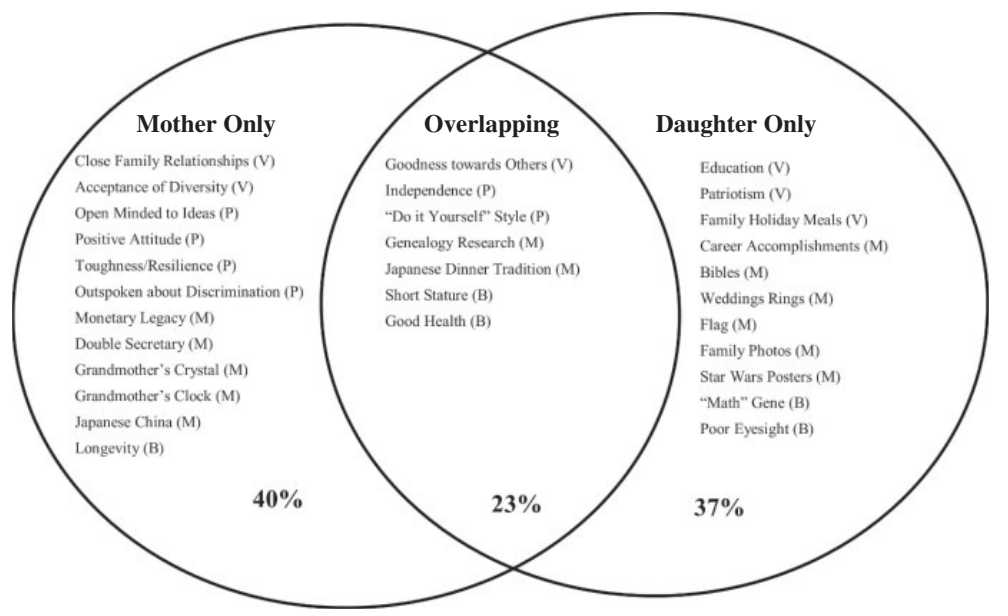

Figure I. Process of Grounded to Overlap Coding for Mother-Daughter Pair K. 


\section{Analysis}

The model-based, structured interview (described earlier) was utilized in order to quantify legacy examples for subsequent numeric analysis. Participants were encouraged to give all examples they could think of with each prompt. A structured approach, such as this, is necessary for valid quantification of themes from a qualitative interview (Sandelowski, Voils, \& Knafl, 2009). Descriptive statistics were utilized to characterize legacy examples within and by participant type across the sample. Differences were examined via nonparametric comparison.

\section{Results}

Members of all pairs described their mutual relationships as close, reasonably open, sharing of similar values, and involving minor to no conflict. This is, perhaps, not surprising in a volunteer sample for an interview study (i.e., those with poor relationships might not see a value in volunteering). While there were some differences among pairs (e.g., Pair C discussed a period of estrangement followed by renewed relationship), these were all close and loving parent-child pairings. No clear differences in relationship quality were identified; although relationship quality is likely relevant to legacy transmission in other contexts (see Discussion section).

\section{QI. Understandings of Legacy}

Parents defined legacy in a number of ways, most in general terms and some with personal examples (see Table 1). Common themes included giving to future generations (i.e., legacy as a gift), being remembered, having an impact years into the future, sharing of stories, and transmission of values. Leading by example was a common theme. Few spoke about material legacies, specifically. Few mentioned their children as distinct legacies; rather, most responded in terms of their impacts on their children and others.

Children expressed a variety of viewpoints (see Table 2). Like their parents, they emphasized values and being remembered, notably stories and specific accomplishments. One emphasized legacy in the context of family history, another in terms of inheriting the "better parts" of someone. Only one spoke about specific persons (grandchildren) as legacies. The general emphasis was on the enduring impacts on those who follow.

Comparison within pairs suggested more differences in understanding of legacy than similarities in this sample. Only four pairs $(\mathrm{C}, \mathrm{H}, \mathrm{K}$, and $\mathrm{M})$ expressed substantially similar understandings before the Typology was presented.

Toward the end of the interview, respondents were asked to predict how much their listing of parental legacies would overlap. All but one respondent chose 4 or higher on the 1 to 7 overlap scale ( $7=$ almost total overlap $)$, suggesting 
Table I. Personal Definitions of Legacy (Parent).

\begin{tabular}{|c|c|c|}
\hline Parent & Definition & Themes \\
\hline A & "Giving of yourself to your children." & Giving \\
\hline B & $\begin{array}{l}\text { "Financial assets that you are going to leave } \\
\text { behind. Or, um, you know, the family heirlooms } \\
\ldots \text { Then came to mind when I was in college } \\
\text { and pledging a sorority, and there was talk } \\
\text { about so and so is a legacy of her mom." }\end{array}$ & $\begin{array}{l}\text { Financial } \\
\text { Heirloom } \\
\text { Pledge }\end{array}$ \\
\hline C & $\begin{array}{l}\text { "It means the things that I leave behind as a result } \\
\text { of the way I impacted other people's lives. I } \\
\text { don't know. I think that's what legacy means } \\
\text { to me." }\end{array}$ & Impacts on others \\
\hline D & $\begin{array}{l}\text { "Something you leave behind in my mind; and I } \\
\text { keep thinking of physical things and inheritance: } \\
\text { this property and stuff like that. I guess I never } \\
\text { thought about it before, but I guess it would be } \\
\text { leaving a sense of responsibility ... honesty" }\end{array}$ & $\begin{array}{l}\text { Property } \\
\text { Values }\end{array}$ \\
\hline E & $\begin{array}{l}\text { "Legacy to me would mean traits that she } \\
\text { (daughter) has that she got from both my } \\
\text { husband and I just by living with us." }\end{array}$ & Traits \\
\hline $\mathrm{F}$ & $\begin{array}{l}\text { “Being remembered. A gift. You don't buy lega- } \\
\text { cies. They are given, freely given. Freely } \\
\text { received. You don't buy, don't earn it. It is a } \\
\text { free gift. And, especially in this sense and I think } \\
\text { of my definition which is very much on my } \\
\text { mind right now. Two kids in college, and one } \\
\text { going. Schools would give legacies because (a } \\
\text { parent) went to school there.” }\end{array}$ & $\begin{array}{l}\text { Gifts } \\
\text { Freely given }\end{array}$ \\
\hline G & $\begin{array}{l}\text { "You go through life and you have certain habits } \\
\text { that you've picked up and, I guess ... your } \\
\text { children and other people that you're around a } \\
\text { lot notice those things about you, that you do. } \\
\text { So I guess they just kind of expect you to react } \\
\text { in a certain way in different situations. So I } \\
\text { guess that's a part of legacy, I suppose." }\end{array}$ & $\begin{array}{l}\text { Habits } \\
\text { Behaviors }\end{array}$ \\
\hline $\mathrm{H}$ & $\begin{array}{l}\text { "The beliefs I have; the kind of work that I do ... } \\
\text { At least my perspective on the world. And my } \\
\text { approach to doing work..." }\end{array}$ & $\begin{array}{l}\text { Beliefs } \\
\text { Work } \\
\text { Perspectives }\end{array}$ \\
\hline I & $\begin{array}{l}\text { "I can see it in two ways. One would be the legacy } \\
\text { I had on my students and on my kids. And, um, } \\
\text { my students, I always focused on making them } \\
\text { professionals, well-grounded professionals. } \\
\text { And with my kids, I would say my number one }\end{array}$ & $\begin{array}{l}\text { Impacts on Others } \\
\text { Mentorship } \\
\text { Goodness }\end{array}$ \\
\hline
\end{tabular}


Table I. Continued.

\begin{tabular}{lll}
\hline Parent & \multicolumn{1}{c}{ Definition } & Themes \\
\hline & thing is that I wanted to be a friend and I want \\
them to be good people. And I think they are & \\
very good people." & \\
"Legacy is what I would leave behind. Legacy is & Gifts \\
the lasting gift that perhaps has an impact on & Things left \\
people's lives 20 years down the road." & Future impacts \\
"I was wondering about that when I saw this & Things left \\
study. It made (me think of) something you pass & \\
on to others. What do you leave behind?" & \\
"I ended up a poor man. I wrote a letter to all of & Values \\
my grandchildren when I was 70.... I said that I & Goodness \\
am not a grandfather that can leave homes, & \\
property. ... This is what I can leave. I would \\
think of my personal legacy as Christian values, \\
a life that was spent in seeking to do good for \\
others ... these values have been passed on."
\end{tabular}

a general expectation of similarity in views on parental legacy. Half chose the same number independently, indicating shared beliefs about mutual understanding of legacy. Of the remainder, only one pair $(F)$ chose ratings separated by more than one digit on this scale. Where differences were present, in every case the parent estimated the overlap higher than did the child.

\section{Q2. Overlap in Views of Parental Legacy}

Venn diagrams were generated for all pairs listing coded legacy examples unique to each individual and shared (overlapping). All pairs estimated at least moderate overlap of views during the interview phase. Mean overlap was 5.4 for parents and 5.0 for adult children. Coded overlap percentages ranged from $15 \%$ 
Table 2. Personal Definitions of Legacy (Child).

\begin{tabular}{|c|c|c|}
\hline Child & Personal legacy definition & Themes \\
\hline A & $\begin{array}{l}\text { "Being able to share something that I find of value } \\
\text {... whatever it is, even if it's teaching my } \\
\text { grandchildren how to create art, to do activi- } \\
\text { ties. I like to take people places. If my grand- } \\
\text { children aren't available to do it, I get exchange } \\
\text { students. And (I) share all of St. Louis with } \\
\text { them. It's important to me. So that's how I feel } \\
\text { about legacies. It may not always be financial; } \\
\text { it's oftentimes creative or teaching and sharing } \\
\text { of the wonder I see out there." }\end{array}$ & $\begin{array}{l}\text { Sharing values } \\
\text { Financial } \\
\text { Teaching } \\
\text { Sharing wonder }\end{array}$ \\
\hline B & $\begin{array}{l}\text { "The values and the things that seem most } \\
\text { important and how there passed on to gener- } \\
\text { ations that follow." }\end{array}$ & $\begin{array}{l}\text { Values } \\
\text { Things left }\end{array}$ \\
\hline C & $\begin{array}{l}\text { "It is things you leave with people. In my rela- } \\
\text { tionships, it is the influence that somebody has } \\
\text { left on me. To me, it is not about customs or } \\
\text { anything. It is about how they lived their life } \\
\text { and then how I pattern my life is similar." }\end{array}$ & Things left \\
\hline D & $\begin{array}{l}\text { "I have kind of been kicking it around in my head a } \\
\text { little bit and I kind of. .. (pause) So I think to } \\
\text { myself: What would people think when I pass } \\
\text { away or what would ... ? (pause) I really don't } \\
\text { know what people think of me and I particu- } \\
\text { larly don't care." }\end{array}$ & Remembrances \\
\hline E & $\begin{array}{l}\text { "Legacy is something that someone ... (pause) I } \\
\text { call it a gift that someone gives to you that } \\
\text { impacts your life and, therefore, impacts the } \\
\text { lives around you. And by her (mother) } \\
\text { impacting my life, my life impacts my family's } \\
\text { life, and my legacy... and because of all of that } \\
\text { it will impact their lives and their children. } \\
\text { Because that's what happens." }\end{array}$ & $\begin{array}{l}\text { Gifts } \\
\text { Impacts } \\
\text { Across generations }\end{array}$ \\
\hline $\mathrm{F}$ & $\begin{array}{l}\text { "I think legacy is like you take on what somebody } \\
\text { has given you and take their better parts. And } \\
\text { you want to make it better, so the next person } \\
\text { and next generation can feel that they gave or } \\
\text { they've done." }\end{array}$ & $\begin{array}{l}\text { Gifts } \\
\text { Better parts }\end{array}$ \\
\hline G & $\begin{array}{l}\text { "Almost a historical perspective of ... a person, } \\
\text { place, or thing. I mean, I work in IT, so, gen- } \\
\text { erally, legacy means something that's been } \\
\text { around, may not necessarily be the go-to }\end{array}$ & $\begin{array}{c}\text { Historical perspectives } \\
\text { and remembrances }\end{array}$ \\
\hline
\end{tabular}


Table 2. Continued.

\begin{tabular}{|c|c|c|}
\hline Child & Personal legacy definition & Themes \\
\hline & $\begin{array}{l}\text { anymore, but it's still relevant. As far as people } \\
\text { or even, you know, my dad, you hear the lasting } \\
\text { legacy of a person; it's kind of the first thing you } \\
\text { think about when you think of that person." }\end{array}$ & \\
\hline $\mathrm{H}$ & $\begin{array}{l}\text { "I guess I tend to think about a legacy being } \\
\text { something that people achieve through, um, } \\
\text { like more often I guess through their work, or } \\
\text { that's the context that I think about. It's like, } \\
\text { um, sort of professional things that people } \\
\text { achieve in then they're able to... have as a } \\
\text { leftover as their gone." }\end{array}$ & $\begin{array}{l}\text { Professional } \\
\text { Achievement } \\
\text { Things left }\end{array}$ \\
\hline I & $\begin{array}{l}\text { "The way generations-the younger generations } \\
\text { and people - are going to perceive you past } \\
\text { your time that you're alive ... and your story } \\
\text { and the retelling; how the picture is painted of } \\
\text { you." }\end{array}$ & $\begin{array}{l}\text { Your story } \\
\text { Remembrances }\end{array}$ \\
\hline J & $\begin{array}{l}\text { "Well, I think that my mom's legacy. When I think } \\
\text { of legacy, I think of Paul and Emma and Tommy, } \\
\text { since right now they're that next generation ... } \\
\text { that's going to continue on after we're gone. } \\
\text { And so my mom, um she has really prioritized } \\
\text { her grandchildren in getting to know them and } \\
\text { wanting to be a part of her life." }\end{array}$ & Grandchildren \\
\hline K & $\begin{array}{l}\text { "I guess what people leave behind after they are } \\
\text { dead." }\end{array}$ & Things left \\
\hline L & $\begin{array}{l}\text { "What you leave behind for people to remember } \\
\text { you by. I think the first people are your family. } \\
\text { What you want to be remembered for." }\end{array}$ & $\begin{array}{l}\text { Remembrances } \\
\text { Remembered for .. }\end{array}$ \\
\hline M & $\begin{array}{l}\text { "Legacy to me is about leaving memories, leaving } \\
\text { life stories, leaving a path to follow ... to be a } \\
\text { good person. To tell a story of hurting and } \\
\text { hardship and what you've had to go through } \\
\text { and how you've overcome all kinds of things." }\end{array}$ & $\begin{array}{l}\text { Story } \\
\text { Example } \\
\text { Inspiration }\end{array}$ \\
\hline $\mathrm{N}$ & $\begin{array}{l}\text { "Something that I believe, something that I rep- } \\
\text { resent and that I will leave with my children. } \\
\text { Something that my parents have worked very } \\
\text { hard at to build up a name for themselves and } \\
\text { they are passing it down to their children. Not } \\
\text { necessarily something that is intentional, but I } \\
\text { think it is also based on who they are as } \\
\text { people, their values.... Something passed from } \\
\text { generation to generation." }\end{array}$ & $\begin{array}{l}\text { Symbols } \\
\text { Values } \\
\text { Across generations }\end{array}$ \\
\hline
\end{tabular}


to $34 \%$ (Mean 27\%), showing no consistent relationship to participant estimates. Pair M, for example, predicted very high overlap (7 and 6 ratings) but yielded the lowest overlap percentage $(15 \%)$ after coding. In contrast, Pair I predicated the lowest overlap (4 and 3 ratings), but coding revealed an overlap percentage $(25 \%)$ close to the sample mean.

In every pair, two thirds or more of total legacy examples were unique to the parent and child. In most pairs, the overlap percentage was the lowest of the group. One notable exception was Pair F where the unique child portion was just $16 \%$. This child chose " 4 " on the 1 to 7 overlap scale in contrast to the parent's choice of "6," indicating an expectation of lower shared understanding on the part of the child. This was confirmed in the parent's longer list of unique examples $(55 \%)$.

Legacy examples within the four primary categories (Values, Personality, Material, and Biological) were examined to answer Questions 2a (differences within pairs) and $2 b$ (differences across groups - parent vs. child).

Within pairs, proportions of legacy examples varied widely across categories. Only three pairs demonstrated relatively high shared views ( $\geq 40 \%$ overlap) on two categories. Pairs E and F agreed on Values and Personality, whereas Pair J agreed on Values and Biological. In half of all pairs, there was no shared understanding of material legacy at all-zero overlap in material examples between them. Mean material overlap was $13 \%$ for all pairs combined.

Individual differences were evident in many pairs with respect to parent versus child perceptions. In Pair B, for example, the son generated no unique examples for values or personality legacies yet had many for material and biological. Across the sample, parents identified more distinct biological (42\%) and values legacies $(35 \%)$ than did their children ( $26 \%$ and $28 \%$, respectively).

\section{Q3. Participant Experiences of Legacy Discussion}

All parents in this study found the interview experience to be enjoyable and interesting. Said Parent D: "I would say enlightening. It is making me think about things that I wasn't. I don't know, I just don't think about them often. I am glad I did it." Some parents reported new learning about themselves, while others found the experience validating of what they already knew or motivating for new legacy creation. Most appreciated the structured approach which guided their self-reflection.

Children reported similar benefits. Many commented on the self-reflection aspects of sitting for such an interview. For some, it piqued their curiosity about the subject in general and as applied to their own families. Said Child G:

It's been interesting, because it's made me think about a lot of things that I've never actually thought about before. I've actually thought more about the legacy 
my grandpa has left and it's because he's no longer with us. But there's a lot of differences in the legacy that he left that I see for my dad.

For both parents and children, it was clear that this research interview was the beginning of something they intended to continue. Said Parent B toward the end of her interview: "After he (son) does his (interview), we are going to go out and have a drink and pizza and we'll talk about it." A number of other participants expressed the same sentiment. This research interview sparked a desire for additional dialogue on the topic of legacy.

\section{Cross-Cultural Differences}

Differences in unique and overlap legacy examples were examined based on national origin of the participants (United States vs. South Africa) via the Mann-Whitney $U$, a nonparametric alternative to the $t$ test. A number of significant differences were identified in this small sample comparison: South African parents identified more unique personality legacies than did U.S. parents (Mean Ranks 9.5 vs. 7.0, $p<.04$ ); South African children identified more unique values legacies than did U.S. children (12.7 vs. $6.1, p<.02)$; South African pairs overlapped in values examples more than did U.S. pairs (11.5 vs. $6.4, p<.05)$; and U.S. pairs overlapped in personality examples more than did South African pairs (8.8 vs. $2.8, p<.03)$.

\section{Discussion}

This mixed-methods study examined legacy beliefs across generations in a volunteer sample of 14 older parent and adult child pairs. This work builds and expands on an existing typology of legacy beliefs (Hunter \& Rowles, 2005). While all persons leave legacies of one form or another, outside of formal life review interventions few older adults are encouraged or directed to discuss and share personal legacy beliefs (Meuser, 2011). Older parents may believe that their children understand their legacies as they do but is this actually the case? Might there be added comfort for older parents in the knowledge that their offspring truly understand them and what they leave? This exploratory study was based on the proposition that well-being may be enhanced in advancing age through shared legacy discussion between generations. Our findings lend support to this idea with some interesting nuances.

Our volunteer participants were clearly motivated for such discussions. All framed their parent-child relationships as open and mutually supportive, for example. Most predicted that we, the investigators, would find a moderate to high level of overlap in their shared views of parental legacy. Said one daughter (Pair J): "I'll say six because I don't know if it's exactly the same as mine but, I would say, I would think there would be a whole lot of overlap." The actual 
overlap for this pair was $27 \%$, near the sample mean. Unique perspectives on parental legacy - from parent and child-accounted for the largest share of legacy examples for all the pairs we interviewed. Most way overestimated their mutual understanding of parent legacy. Our data indicate that, even in the closest relationships, legacy beliefs differ widely and so there is room for greater mutual understanding (i.e., parent to child, child to parent).

With respect to legacy types, we found that participants benefited from specific prompts from the Hunter and Rowles Typology. Our interviews started general in nature ("tell about your legacy ...") and became increasingly specific with handouts from the model. This structure grounded the discussion and provided opportunities for new self-reflection, as evidenced in later comments concerning benefit. This study lends support to the validity of the original model and expands it to more fully capture legacy examples with stylistic and creative characteristics. Despite over a decade in the literature, the 2005 paper detailing the Hunter and Rowles model has been cited just 80 times. ${ }^{4}$ Our study supports the utility of the model for identifying legacy beliefs and differences across family members.

We examined the unique examples identified by parents and children, as well as the overlap between them. One substantial and interesting difference was identified with respect to overlapping views of parental material legacy. A common first example of legacy is material, often financial or property-related (Hunter \& Rowles, 2005). Most of us leave wills to define such legacies. Six pairs in our study had no overlap at all in this domain, and the mean overlap percentage for material legacy $(13 \%)$ was well below those of the other three legacy types. It is interesting to speculate on this difference as a possible generational difference in valuing of material legacies. Further research is needed to understand it.

Parents and children entered this study with largely different understandings of legacy as a construct, learned from the Hunter and Rowles model, and finished feeling engaged and motivated for further reflection on this topic. In practice, administering our interview felt, subjectively, like an intervention was taking place. A number of respondents cried and commented on the personal value of this type of discussion. Our interviews didn't just gather research data but also had the secondary effect of fostering new learning and growth in our participants. This speaks to the value of the original model and our expansion for future intervention research. An area for legacy intervention might be hospice care, where death is near and the opportunity for legacy discussion may be especially welcome and potentially impactful. A next step for our research team is to repackage our protocol and pilot test it as a hospice intervention.

\section{Limitations}

This study is not without limitations. While we interviewed twice the number of individuals as in the original Hunter and Rowles study, our main focus was on 
just 14 pairs. All volunteered out of curiosity and interest in this topic, and so are unlikely to represent the larger population of older parents and adult children. Only two racial groups were represented: White and Mixed Race. No African Americans, Hispanics, Asians, or other racial-ethnic groups volunteered to participate. That said, to our knowledge, this study is the first of its kind and so represents a starting point. Examination of between-group differences is a worthy objective for future research.

\section{Cross-Cultural Comparison}

Another issue is the cross-national aspect of this work. This project was conceived pursuant to a cross-cultural faculty exchange grant awarded to the lead authors (Meuser, Mthembu). The three mixed race pairs were from Cape Town, SA. All participants were English speaking and participated in the same interview protocol as U.S. pairs. Our working hypothesis was that legacy beliefs are so individual in nature that cross-cultural influences would pale in comparison to individual differences. This is open to debate, however.

South Africa has many cultural underpinnings, tribal and colonial. Mixed race individuals were part of South African culture from early in the colonial period (1700s), as White Dutch and British settlers intermarried. They enjoyed voting, commercial and other societal rights for over a century until apartheid began and many rights were stripped (Rissik, 2011). The Population Registration Act of 1950 placed colored people between Whites and Blacks with respect to class and political rights (Posel, 2001). This disjointed history reverberates today as mixed race persons strive to reestablish their property, worth and identity. Such history is foreign to U.S. Whites.

While our sample is small for cross-cultural comparisons, we did find some interesting signals suggesting a role for culture in legacy beliefs. South African pairs agreed on values-based legacies more so than their U.S. counterparts. Conversely, U.S. pairs agreed more with respect to personality legacies. These differences may only have meaning in our small sample. While more research is needed to know, an internal versus external framing could suggest an explanation and an approach. Might cultural experiences of oppression encourage mutual exploration of internal, heartfelt values? Might cultural experiences in a secular democracy (i.e., without oppression) encourage more mutual focus on external style? If so, might African Americans be similar to mixed race South Africans with respect to legacy beliefs? These kinds of questions are worth exploring.

Before doing so, however, a standardized approach to quantify legacy beliefs is needed. We have developed a quantitative questionnaire based on our qualitative interview for administration to a new sample of older parent and adult child pairs in both countries. A reliable, valid measure of legacy beliefs is the desired outcome. Additional quantitative studies will follow. 


\section{Declaration of Conflicting Interests}

The authors declared no potential conflicts of interest with respect to the research, authorship, and/or publication of this article.

\section{Funding}

The authors disclosed receipt of the following financial support for the research, authorship, and/or publication of this article: This research was made possible by a faculty exchange and pilot research grant from the University of Missouri South African Education Program.

\section{ORCID iD}

Thuli G. Mthembu (D) http://orcid.org/0000-0002-1140-7725

\section{Notes}

1. See http://www.umsl.edu/gerontology/Life\%20Review\%20Project/.

2. The University of Missouri System has a 30-year relationship with the University of the Western Cape in Cape Town, South Africa, to promote education and research exchanges. Authors (Meuser, Mthembu, Overton) were recipients of exchange grants during the 2016-2017 academic year.

3. The interview protocol may be viewed online at https://sites.google.com/a/umsl.edu/ legacy-interview-protocol/.

4. Per a Google Scholar search on November 13, 2017.

\section{References}

Allen, R. S. (2009). The legacy project intervention to enhance meaningful family interactions: Case examples. Clinical Gerontologist, 32(2), 164-176.

Baker, L. M. (2004). Information needs at the end of life: A content analysis of one person's story. Journal of the Medical Library Association, 92(1), 78-82.

Butler, R. N. (1963). The life review: An interpretation of reminiscence in the aged. Psychiatry, 26(1), 65-76.

de Witt, L., Campbell, L., Ploeg, J., Kemp, C. L., \& Rosenthal, C. (2013). "You're saying something by giving things to them:" Communication and family inheritance. European Journal of Ageing, 10(3), 181-189.

Ehlman, K., \& Ligon, M. (2012). The application of a generativity model for older adults. The International Journal of Aging \& Human Development, 74(4), 331-344.

Erikson, E., \& Erikson, J. (1981). On generativity and identity: From a conversation with Erik and Joan Erikson. Harvard Educational Review, 51(2), 249-269.

Erikson, E. H. (1963). Childhood and society (2nd ed.). New York, NY: Norton.

Garland, J., \& Garland, C. (2001). Life review in health and social care: A practitioner's guide. Philadelphia, PA: Taylor \& Francis.

Gibson, F. (2004). The past in the present: Using reminiscence in health and social care. Baltimore, MD: Health Professions. 
Haight, B. K., \& Haight, B. S. (2007). The handbook of structured life review. Baltimore, MD: Health Professions.

Hunter, E. G. (2008). Beyond death: Inheriting the past and giving to the future, transmitting the legacy of one's self. OMEGA-Journal of Death and Dying, 56(4), 313-329.

Hunter, E. G., \& Rowles, G. D. (2005). Leaving a legacy: Toward a typology. Journal of Aging Studies, 19(3), 327-347.

Kenyon, G. M., Bohlmeijer, E., \& Randall, W. L. (Eds.). (2011). Storying Later Life: Issues, Investigations, and Interventions in Narrative Gerontology. New York, NY: Oxford University Press.

King, D. A., \& Wynne, L. C. (2004). The emergence of "family integrity" in later life. Family Process, 43(1), 7-21.

Kunz, J. A., \& Soltys, F. G. (2007). Transformational reminiscence: Life story work. New York, NY: Springer.

McAdams, D. P. (1996). Narrating the self in adulthood. In G. Kenyon, J. E. Birren, J. Ruth, J. J. F. Schroots, \& T. Svensson (Eds.), Aging and biography: Explorations in adult development (pp. 131-148). New York, NY: Springer Publishing Company.

McClement, S., Chochinov, H. M., Hack, T., Hassard, T., Kristjanson, L. J., \& Harlos, M. (2007). Dignity therapy: Family member perspectives. Journal of Palliative Medicine, 10(5), 1076-1082.

Meuser, T. M. (2011). Oral life review in older adults: Principles for the professional. In P. E. Hartman-Stein \& A. L. La Rue (Eds.), Enhancing cognitive fitness in adults: A handbook for the development of community-based programs. New York, NY: Springer Publishing Company.

Murray, S. A., Kendall, M., Boyd, K., Worth, A., \& Benton, T. F. (2004). Exploring the spiritual needs of people dying of lung cancer or heart failure: A prospective qualitative interview study of patients and their carers. Palliative Medicine, 18(1), 39-45.

Newton, N. J., \& Jones, B. K. (2016). Passing on: Personal attributes associated with midlife expressions of intended legacies. Developmental Psychology, 52(2), 341-353.

Posel, D. (2001). Race as common sense: Racial classification in twentieth-century South Africa. African Studies Review, 44(2), 87-113.

Randall, W. L., \& Kenyon, G. M. (2004). Time, story, and wisdom: Emerging themes in narrative gerontology. Canadian Journal on Aging/La Revue canadienne du vieillissement, 23(4), 333-346.

Rissik, D. (2011). Culture shock: A survival guide to customs and etiquette. Tarrytown, NY: Marshall Cavendish International.

Sandelowski, M., Voils, C. I., \& Knafl, G. (2009). On quantitizing. Journal of Mixed Methods Research, 3(3), 208-222.

Schaie, K. W., \& Willis, S. L. (2000). A stage theory model of adult cognitive development revised. In R. L. Rubinstein, M. Moss, \& M. H. Kleban (Eds.), The many dimensions of aging (pp. 175-193). New York, NY: Springer Publishing Company.

Sheehan, N. W., \& Donorfio, L. M. (1999). Efforts to create meaning in the relationship between aging mothers and their caregiving daughters: A qualitative study of caregiving. Journal of Aging Studies, 13(2), 161-176.

Zacher, H., Rosing, K., \& Frese, M. (2011). Age and leadership: The moderating role of legacy beliefs. The Leadership Quarterly, 22(1), 43-50. 
Zanjani, F., Downer, B. G., Hosier, A. F., \& Watkins, J. D. (2015). Memory banking: A life story intervention for aging preparation and mental health promotion. Journal of Aging and Health, 27(2), 355-376.

Zaval, L., Markowitz, E. M., \& Weber, E. U. (2015). How will I be remembered? Conserving the environment for the sake of one's legacy. Psychological Science, 26(2), 231-236.

\section{Author Biographies}

Thomas M. Meuser, PhD, is a professor in the Department of Sociology, Gerontology \& Gender at the University of Missouri - St. Louis (UMSL). He serves as director of the Gerontology Program and coordinator for the UMSL Life Review Project. His research interests include reminiscence and life review in aging, losses and transitions in aging, driver fitness and alternative transportation, and dementia care.

Thuli G. Mthembu, $\mathrm{PhD}$, is a lecturer in the Department of Occupational Therapy at the University of the Western Cape, Cape Town, South Africa. His research interests include chronic diseases, trauma, aging, and spiritual care.

Brianne L. Overton, MA, MEd, is a doctoral student in Counselor Education at the University of Missouri - St. Louis. Her research interests include grief and dying in childhood and young adulthood, anticipatory grief processes, and psychotherapeutic intervention.

Nicolette V. Roman, PhD, is a professor of Social Work and head of the Child and Family Welfare Studies Program at the University of the Western Cape, Cape Town, South Africa. Her research interests include psychological well being in families, family resilience, youth development, and parenting processes.

Rebecca D. Miller, MA, is a graduate student in Counselor Education at the University of Missouri - St. Louis.

Katharina P. Lyons, was a graduate student in Counselor Education at the University of Missouri - St. Louis at the time of this work.

Brian D. Carpenter, $\mathrm{PhD}$, is a professor of Psychological \& Brain Sciences at Washington University in St. Louis. His research focuses on family relationships in late life, with a particular emphasis on collaborative family communication and decision-making. Other research activities focus on older patient-physician interactions, knowledge about Alzheimer's disease, and mental health issues at the end of life. 